\title{
The Lifelong Learning Iceberg of Information Systems Academics - A Study of On-Going Formal and Informal Learning by Academics
}

\author{
Bill Davey \\ School of Business \\ Information Technology, \\ RMIT University, Australia
}

Bill.Davey@rmit.edu.au

\author{
Arthur Tatnall \\ Centre for International Corporate \\ Governance Research, \\ Victoria University, Australia
}

Arthur.Tatnall@vu.edu.au

\section{Executive Summary}

This article describes a study that examined the lifelong learning of information systems academics in relation to their normal work. It begins by considering the concept of lifelong learning, its relationship to real-life learning and that lifelong learning should encompass the whole spectrum of formal, non-formal and informal learning. Most world governments had recognised the importance of support for lifelong learning. Borrowing ideas and techniques use by Livingstone in a large-scale 1998 survey of the informal learning activities of Canadian adults, the study reported in this article sought to uncover those aspects of information systems academics' lifelong learning that might lead policy setters to understand the sources of learning valued by these academics. It could be argued that in the past the university sector was a leader in promoting the lifelong learning of its academic staff, but recent changes in the university environment around the world have moved away from this ideal and academics interviewed from many countries all report rapidly decreasing resources available for academic support. In this environment it is important to determine which learning sources are valued by information systems academic so that informed decisions can be made on support priorities.

In the study, thirty six interviews were conducted with fully qualified and tenured academics selected from Information Systems Schools in sixteen universities across eleven countries. In relation to their own on-going learning, after completion of their formal academic qualifications, the study found that academics do not value formal learning as much as they do informal learning. The most valued informal learning methods involve structured ways for academics to interact with other academics. These activities included conference attendance and use of the Internet as a portal to both static sources and interactions with other people. The study showed that many IS academics value academic conferences highly and think that their research and teaching benefit

Material published as part of this publication, either on-line or in print, is copyrighted by the Informing Science Institute. Permission to make digital or paper copy of part or all of these works for personal or classroom use is granted without fee provided that the copies are not made or distributed for profit or commercial advantage AND that copies 1) bear this notice in full and 2) give the full citation on the first page. It is permissible to abstract these works so long as credit is given. To copy in all other cases or to republish or to post on a server or to redistribute to lists requires specific permission and payment of a fee. Contact Publisher@InformingScience.org to request redistribution permission. greatly by the currency of the ideas presented and the interactions that take place. This finding should be of interest to university policy makers who determine funding for informal learning activities such as attendance at academic conferences.

Keywords: Lifelong learning, information systems academics, informal learning, academic policy. 


\section{Introduction}

UNESCO adopted Lifelong Learning as a master concept in 1970 (Tight, 1998) as the culmination of efforts by many people to have recognised the relationship between investment in education of whole populations and economic and social outcomes. By the end of the century most world governments had recognised the importance of support for lifelong learning. The British Education Secretary David Blunkett (1998) noted that: "In the $21^{\text {st }}$ century learning at different stages in life will be essential as human capital becomes to the information revolution what fixed capital was to the industrial revolution."

Field (2000) cites evidence suggesting that in Canada the proportion of adults involved in organised learning rose from $20 \%$ in the mid-1980s to $38 \%$ in the mid-1990s. Estimates for the USA are for a $46 \%$ participation rate in adult learning in 1999, which represents growth of about onethird since 1991. In Finland participation in organised adult learning increased 28\% between 1972 and 1995, while in the Netherlands participation rose from $15 \%$ in the 1960 s to 20 per cent in the 1980 s and had reached almost $38 \%$ by the mid-1990s (Field, 2000). Whether mature graduates gain sufficiently to make learning a worthwhile investment remains undecided, with one recent study suggesting that it may not be a good investment for many mature graduates, at least when returns are measured solely in income terms. There is an absence of research on the returns of other kinds of qualifications for adult learners in the British economy, and on learning that may not result in a qualification (Jenkins, Vignoles, Wolf, \& Galindo-Rueda, 2002).

In a publication resulting from a recent IFIP conference on 'ICT and Real-Life Learning' Mike Kendall (2005) takes the position that real-life learning and lifelong learning are, in effect, the same activity with different names. Kendall goes on to argue that lifelong learning will continue to gain in prominence, and explores the relationship between lifelong learning and informal learning styles as well as how this relates to vocational and professional education. At the same conference Tom van Weert (2005) pointed out that students of higher education can make good use of real-life learning environments where they can learn to deal with knowledge work processes using real-life examples. While these and many other papers often speak of the value of life-long and real-life learning for our students, in this article we argue that learning of this type is also of value to university academics.

\section{Lifelong Learning}

The European Commission defines lifelong learning as "Any learning activity undertaken throughout life, with the aim of improving knowledge, skills and competences within a personal, civic, social and/or employment-related perspective." (European Commission, 2001) In addition to the emphasis it places on learning from pre-school to post-retirement, lifelong learning should encompass the whole spectrum of formal, non-formal and informal learning (European Commission, 2001). In 1998 Livingstone conducted a large-scale, country-wide survey in Canada of the informal learning activities of Canadian adults $(\mathrm{N}=1562)$ that indicated an increase in the incidence of informal learning and that people in virtually all walks of life exhibited similar patterns of incidence of informal learning (Livingstone, 1999). In the study, Livingstone ( Livingstone; 1999; NALL Research Network, 2007) recognises two stages of formal education: 'Formal Schooling' - the compulsory schooling related to age, and 'Further Education' covering all other formal classes organised for adults. This study also investigates 'Explicit Informal Learning' and 'Tacit Informal Learning' and Livingstone distinguishes explicit informal learning from more tacit informal learning by considering the subject's own conscious identification of the activity as 'significant' learning. "The important criteria that distinguish explicit informal learning are the retrospective recognition of both a new significant form of knowledge, understanding or skill ac- 
quired on your own initiative and also recognition of the process of acquisition." (Livingstone, 1999, p. 4)

We have used the Livingstone distinctions so as to allow comparison with these results, but the distinctions between learning types are also particularly apt for our population. Our population have finished their formal schooling, but have an interest in a variety of further education activities. Even if they are fully qualified in their own academic field, Information Systems (IS) academics often take part in extra degree programs to round their skills. This is often in tertiary teaching courses. They also undertake industry-based classes to learn about new Information Technology (IT) products. Other explicit informal learning comes from that arising from a research project. Anecdotally, IS academics often report incidental or tacit learning from encounters with industry figures and fellow academics.

\section{Lifelong Learning and Academic Policy}

European policy (European Commission, 2001), and the work of many individual countries (Askling \& Foss-Fridlizius, 2000) shows that governments have invested heavily in support for lifelong learning. It could be argued that in the past the university sector was a leader in promoting the lifelong learning of its academic staff. Recent changes in the university environment around the world, however, have moved away from this ideal and academics interviewed from the USA, UK, parts of Europe and Australia all report rapidly decreasing resources available for academic support. In most countries the levels of government funding of universities has been steadily decreasing and academic resources are being more closely tied to direct income sources. In this environment it is important to determine which learning sources are valued by these academic so that informed decisions can be made on support priorities.

\section{The Study}

The Livingstone study (Livingstone, 1999) is the most comprehensive study of informal learning available and it was decided to follow the method of this study so as to allow comparison of results. The survey consisted of 171 questions, many quite specific to the Canadian population surveyed, but some very relevant and useful for our survey. A full copy of the survey can be found in a document published by the National Research Network for New Approaches to Lifelong Learning (NALL Research Network, 2007). A key question in this study was:

"Everybody does some informal learning outside of formal classes or organized programs. You may spend a little time or a lot of time on it. It includes anything you do to gain knowledge, skill or understanding from learning about your health or hobbies, to household tasks or paid work, or anything else that interests you. Please begin to think about any informal learning you have done during the last year outside of formal or organized courses." (NALL Research Network, 2007, p. 11)

In the following sections of the interview schedule, respondents were asked about informal learning related to community work (including fund-raising, organisational or managerial skills, social issues, communication skills, interpersonal skills, other technical skills, other skills or knowledge), household work (including home maintenance, cooking, cleaning, child or elder care, shopping for groceries or clothes etc, home renovation and gardening, home budgeting and other household tasks), other general interests (including sports or recreation, practical skills, cultural traditions or customs, leisure or hobby skills, social skills and personal development, health and wellbeing, finances, computer skills, language skills, science and technology, intimate relationships, religion or spirituality, environmental issues, pet care, public and political issues) and other informal learning not directly related to employment, community activities or housework. 
Our survey was conducted, mostly by semi-structured personal interview, with fully qualified IS academics (those with a doctoral degree) who had permanent academic positions. Some telephone and Internet data collection was also undertaken. The first questions asked were designed to ascertain the interview subject's views on their undertaking of informal learning, compared with formal learning. Later detailed questions were restricted to informal learning related to vocation.

The following was part of the introduction for participants:

Every academic does some informal learning outside of formal classes or organised programs. You may spend a little time or a lot of time at it. It includes anything you do to gain knowledge, skill or understanding from learning about your health or hobbies, household tasks or paid work, or anything else that interests you. Please begin to think about any informal learning you have done during the last year outside of formal or organised courses. First, let's talk about any informal learning activities outside of courses that have some connection with your current or possible future paid employment. This could be any learning you did on your own or in groups with colleagues, that is, any informal learning you consider to be related to your employment.

For this study participants were chosen from 'fully qualified' academics. In United States terms these are tenured faculty while in Australia, Europe and the UK they are IS academics with a completed doctoral qualification and permanent full-time Information Systems positions in a university. This level of seniority was chosen to avoid confusion between educational activities chosen by the person for their own interest, rather than those required to achieve tenure. Respondents represented full-time academics from Australia, UK, Netherlands, Spain, USA, Canada, Japan, China, Sweden, Norway and Finland. Respondents were mostly academics with significant teaching responsibilities and a small number of research-only academics. Following the Livingstone methodology (Livingstone, 1999), respondents were given a short explanation of the types of learning being investigated and then asked about their learning activities for the previous year and their aspirations for the following year. After preliminary interviews it became apparent that academics were uncertain about the inclusion of personal experiences or conference attendance and the extent to which their self-directed research should be included in their responses. These are clearly sources of tacit informal learning and so items were added to the interview plan to allow responses to these issues. Overall the two researchers were able to conduct thirty-six interviews with academics selected from Information Systems Schools in sixteen Universities across eleven countries. These interviews soon began to show some common patterns indicating that further interviews would most likely produce the same result. Nevertheless, a larger study to confirm our results would be worthwhile.

\section{Results}

The reported research was qualitative in nature and so did not concentrate much on collecting statistical information about academics' learning patterns. The data collected was mainly in the form of semi-structured interview narrative, and a short description of the important points is provided below.

\section{Further Formal Education}

Less than $10 \%$ of respondents reported taking part in formal further education activities in the last twelve months. Of those that did, most undertook formal training courses to learn about a new IT software product related to their teaching. Also reported were two people who undertook a formal qualification in tertiary teaching. None of those surveyed had plans for further education in the near future. One respondent indicated that: "It might seem like a contradiction for an educator to 
say this, but I don't see any need for further gaining formal qualifications myself - I already have my PhD. I'm still very interested in learning new things, but I tend to do this informally."

Results indicated that the main reason IS academics undertook formal training courses in new IT products was to reduce the time it would otherwise have taken them to learn on their own. One IS academic indicated that: "Unlike our other university colleagues, we IS academics continually have to learn new products, and time to do this is an issue. If I can learn quickly through attending a course it might be worthwhile." One example of this type of formal learning was that undertaken by a group of ten IS academics from one university who specifically commissioned an industry-based course on Microsoft Visual Basic .Net. All these academics had some knowledge of Visual Basic, but not of the new .Net product. The training organiser for the group spoke with the industry training house and organised training based on the experience and needs of the group. This way they did not waste time in being subjected to things they did not need or want to know, and were not slowed down by other inexperienced people. When questioned, all these academics thought that this approach represented a very efficient method of updating their skills for this new product.

\section{Explicit Informal Learning}

The important criteria that distinguish explicit informal learning are the retrospective recognition of both a new significant form of knowledge, understanding or skill acquired on your own initiative and also recognition of the process of acquisition (Livingstone, 1999).

Respondents unanimously pointed out that the job of an IS academic requires adaptation to new knowledge, in what they reported as much faster rates than for non-IS areas of knowledge. As reported above, some achieved this new knowledge from short courses, but this was almost exclusively related to a specific software product. Some, but not all, of those who had some recent experience with courses of this kind, often provided by the software vendor, expressed dissatisfaction with the effectiveness and quality of the course they had undertaken. All respondents, however, reported valuing their own directed learning. This learning was often described as selfdirected research even when it consisted of self-paced working through an existing text. The most common source of self-directed learning involved use of the Internet, and many respondents reported using Internet based tutorial services from free sites and user group sites. Several academics gave responses like this one: "I find that using the Internet is a good way of finding out these things, but I also like to talk to people if possible."

Far more valued, in terms of quality, was the attendance at targeted sessions at conferences. Respondents reported that the presentations at selected sessions (as opposed to every possible session) at conferences were a major source of inspiration for their subsequent learning activities. "The fastest way to get a new lead into an area you need to investigate is at an appropriate conference session." The type of sessions they particularly appreciated varied and were not always related directly to their own area of specialisation.

\section{Tacit Informal Learning}

By definition, tacit learning can only be uncovered by prompting. Prompts used for this were questions of the type: "for new areas of research or new subjects taught, how did you learn?" This type of prompting then produced ready discussion of tacit learning. The study found that perhaps the most important tacit learning activities resulted from interactions with other IS academics gained by attendance at national and international conferences. Respondents reported that they particularly valued informal interactions of this type but noted that results of such interactions were unpredictable, but that they often led to the generation of significant new ideas, research and 
teaching projects. For example: "I think that you learn a lot at conferences, and not just what you think you might learn before you go."

\section{Conferences and other personal interactions}

The results relating to the perceived value of conference learning are biased in that all respondents from outside Australia were contacted as a result of the research team having met them at conferences. The result figures, however, show no difference in this group from the more heterogeneous group from Australia. In both cases around $65 \%$ of respondents reported that the various learning activities arising from conference attendance were their most valued experience. A further $10 \%$ reported that conferences were their second most valued learning. When questioned in more detail the reasons for this value varied between two alternatives.

The largest group of respondents reported that many of their research ideas and new directions for delivery and content of subject material came from personal interaction with people they met at conferences. For those academics who attended one or more international conferences during the previous twelve months the reported highest value was from the international contacts they made there. One respondent indicated that: "Some people think that the main reason for going to a conference is to listen to the presentations. Of course you do this, but for me the important thing is to meet the presenters." These respondents pointed to the possibility of obtaining new information from academics with similar specialisations. Respondents pointed to the difficulty of relatively small research populations containing sufficient people with convergent interest in narrow areas. One said that: "It is always good to see that you are not alone in your research interests and to make contact with others." A common argument proposed was that an international conference enabled all of the experts in a specialised area to come together. A number of academics also found discussions with international colleagues from related discipline areas to be very valuable, independent of the more formal activities associated with the conferences. Some indicated that it is too easy to get stuck with a local view of a very specific specialisation and to neglect other areas that might be related to it. One example of this was the respondent who discovered a different method of researching her topic at a conference: "I had not heard of Actor-Network Theory before the conference, but it seems exactly the approach I need." These people saw considerable value in more general international information systems conferences. A significant view was that conference attendance also provided information that was more current than that contained in journals, and the opportunity to enter into discussions with the author was valued. Nonetheless, with some notable exceptions, all respondents reported a decrease in support funding from their universities, particularly for international conferences. This apparent trend toward decreased university support of informal learning directly contradicts the value placed on the benefits of attendance at international conferences revealed by the study.

\section{Internet research}

The researchers found that discussions of tacit learning from both research oriented and teaching oriented academics produced a surprised reaction such as this one: "Yes, I have to do a lot of learning to keep up with the latest ideas in my area!" The subsequent discussion introduced many forms of self study and research. From the interviews conducted, all of those interviewed finally listed the Internet as the most important source of this learning, but this might be misleading. In some cases the use of the Internet was as a portal to the university library electronic sources. As this issue did not form part of the original survey there is no data as to the extent to which 'the Internet' was meant in the global sense as opposed to a tool into more local sources. 


\section{Time Spent on Learning}

Another thing Livingstone (1999) notes is the reported time spent on learning activities. In our study, the research team reported general dissatisfaction by participants regarding the quantifying of time spent. One respondent reported having kept a diary for another study and being surprised by the gap between reported time spent and time recorded in the diary. Several respondents reported that informal learning activities took "all the time available." In general the team concluded that academics have little sense of the time they spend performing these informal learning tasks and that any report of time elapsed, as opposed to relative time spent may be misleading.

\section{Conclusion}

As one would expect, the study indicated that fully qualified IS academics felt little need to undertake formal training except for the occasional course to learn about a new IT product. Those who undertook this product training reported that they could have taught themselves from books and help files, but thought this too slow and time consuming. They did the formal training because they saw it as the most time-effective way to learn about this product.

Of the various means of informal learning, two shine out as most important to IS academics: the Internet, and attendance at national and international conferences. Using the Internet has become second nature to most academics who appreciate the ready access it can provide to a wealth of information through the use of search engines and links to journal articles. It provides an important means of informal learning that should be acknowledged. In particular the existence of Internet user group based tutorials was valued highly by some academics.

Among some administrators and academics, conference publications sometimes are viewed as of lesser value than journal publications. While this may well be true in simplistic list-generation and financial terms, it ignores the main reason for attending conferences: to meet and interact with other academics. The study showed that many IS academics value this interaction highly and think that their research and teaching benefit significantly from such interaction. The value in such conferences includes exposure to more current material, the opportunity to exchange ideas directly with authors, and a broader, more global outlook than when one is limited to discourse with local colleagues. Nonetheless, there is evidence of decreased conference funding by universities. Further, results of this study suggest that attempts by universities to substitute in-house training for conference funding are unlikely to meet the lifelong learning needs of their academics. With decreased conference spending by universities, the future of lifelong learning for academics is uncertain. Additional cross-national studies of conference funding patterns could provide insights into the future of lifelong learning for academics around the globe.

Like the Canadian survey (Livingstone, 1999), our research has shown that most learning by academics is informal, and much of it tacit informal. University administrators should be aware that their academic staff value this informal learning (and particularly international conference attendance) very highly as a major component of their lifelong learning.

\section{References}

Askling, B. \& Foss-Fridlizius, R. (2000). Lifelong learning and higher education: The Swedish case. European Journal of Education, 35(3), 257-270.

Blunkett, D. (1998). Opportunities to live and learn. Times Higher Education Supplement. London. 27 Feb 1998.

European Commission. (2001). Making a European area of lifelong learning a reality. Brussels: Commission of the European Communities. 
Lifelong Learning Iceberg of Information Systems Academics

Field, J. (2000). Lifelong learning and the new educational order. Oakhill, Stoke on Trent: Trentham Books.

Jenkins, A., Vignoles, A., Wolf, A., \& Galindo-Rueda, F. (2002). The determinants and effects of lifelong learning. London: Centre for the Economics of Education, London School of Economics and Political Science.

Kendall, M. (2005). Exploring the role of informal learning in real-life learning. In T. van Weert \& A. Tatnall, Information and communication technologies and real-life learning - New education for the knowledge society (pp. 189-196). New York: Springer/IFIP.

Livingstone, D. W. (1999). Exploring the icebergs of adult learning: Findings of the first Canadian survey of Informal Learning Practices. The Canadian Journal for the Study of Adult Education, 13(2), 49-72.

NALL Research Network. (2007). New approaches to lifelong learning. Ontario Institute for Studies in Education of the University of Toronto.

Tight, M. (1998). Lifelong learning: Opportunity or compulsion. British Journal of Educational Studies, 46(3), 251-263.

van Weert, T. (2005). Higher education: Learning in real-life. In T. van Weert \& A. Tatnall, Information and communication technologies and real-life learning - New education for the knowledge society (pp. 131-142). New York: Springer/IFIP

\section{Biographies}

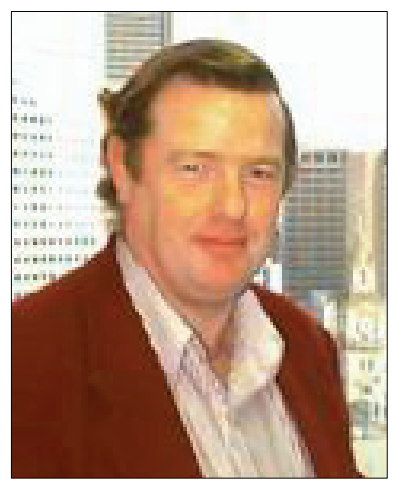

Bill Davey is a Senior Lecturer in the School of Business Information Technology at RMIT University, Melbourne, Australia. He holds bachelors degrees in Science and Education, a Graduate Diploma in Computing, and Master of Business degree. His research interests include methodologies for systems analysis and systems development, Visual Basic programming, information systems curriculum, and information technology in educational management.

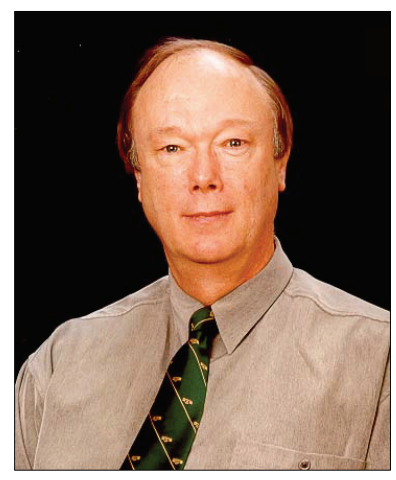

Arthur Tatnall is an Associate Professor in the Graduate School of Business at Victoria University in Melbourne, Australia. He holds bachelors degrees in Science and Education, a Graduate Diploma in Computer Science, and a research Master of Arts in which he explored the origins of Information Systems curriculum in Australian universities. His $\mathrm{PhD}$ involved a socio-technical study in curriculum innovation in which he investigated the manner in which Visual Basic entered the curriculum of an Australian university. His research interests include technological innovation, history of technology, information systems curriculum, project management, electronic commerce, and information technology in educational management. He has just completed editing the Encyclopedia of Portal Technology and Applications.

Arthur and Bill have worked together co-operatively on many occasions. They have co-operated on several joint research projects and co-authored a large number of academic papers, book chapters, and textbooks relating to management information systems, programming, computers in management, and IS curriculum. 